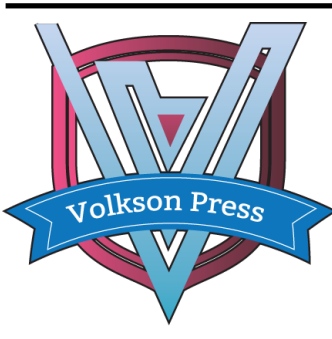

Contents List available at VOLKSON PRESS

New Materials and Intelligent Manufacturing (NMIM) DOI : http://doi.org/10.26480/icnmim.01.2018.83.86

Journal Homepage: https://topicsonchemeng.org.my/

ISBN: 978-1-948012-12-6

\title{
IDENTIFICATIONS ON PURE AND FAKED PEARL LAYER POWDER USING X-RAY DIFFRACTION AND ELECTRON SPIN RESONANCE
}

\author{
Dayong Lu*, Shuai Kang
}

Key Laboratory for Special Functional Materials in Jilin Provincial Universities, Jilin Institute of Chemical Technology Chengde Street 45, Jilin 132022, China.

*Corresponding Author Email: dylu@jlict.edu.cn

This is an open access article distributed under the Creative Commons Attribution License, which permits unrestricted use, distribution, and reproduction in any medium, provided the original work is properly cited

\section{ARTICLE DETAILS}

\section{Article History:}

Received 26 June 2018

Accepted 2 July 2018

Available online 1 August 2018

\begin{abstract}
The high-grade commercially available pearl layer powder (CAPLP, 80 yuan a bottle) and the cheap street pearl powder (CSPP, 10 yuan a bottle) were investigated using X-ray diffraction (XRD) and electron spin resonance (ESR) techniques. The major constituent of CAPLP was identified to be pure pearl powder composed of calcium carbonate $\left(\mathrm{CaCO}_{3}\right)$ with an orthorhombic crystal structure, which should be fabricated by grinding freshwater pearls. CSPP was identified by XRD to be a mixture of scallop shell powder (78\%) and pearl powder (22\%), and therefore CSPP was a fake and shoddy commodity. The major constituent of scallop shell was $\mathrm{CaCO}_{3}$ with a monoclinic crystal structure. The ESR results demonstrated that the concentration of $\mathrm{Mn}^{2+}$ in CAPLP is lowest and that is highest in scallop shell. The ESR also detected Fe impurities in CSPP. The combination of XRD and ESR techniques can set up a rapid detection method for quality control of CAPLP.
\end{abstract}

\section{KEYWORDS}

Pearl powder, X-ray diffraction, crystallized phase, electron spin resonance

\section{INTRODUCTION}

Pearl powder, which is a famous traditional Chinese medicine material, has a history of more than 2000 years in China [1]. Pearl powder is not a pure mineral, but a biomineral containing organic inclusions [2]. It has been widely used in antioxidation, bone repairing, cosmetic, antiaging substance and wound healing process [3-8]. It has been reported that pearl is a calcium-rich source $(\sim 90 \%$ of weight $)$ and it contains amino acids, conchiolin proteins and a small amount of trace elements [9-15]. Pearl powder is divided into two types: seawater pearl powder and freshwater pearl powder. $\mathrm{Pu}$ et al indicated that the former has comparatively abundant $\mathrm{Na}, \mathrm{Sr}, \mathrm{K}, \mathrm{Mg}$ and $\mathrm{B}$, whereas the latter contains relatively rich $\mathrm{Mn}, \mathrm{Ba}$, $\mathrm{Fe}$ and $\mathrm{Cr}$ [14].

Because of great value of pearl powder as medicinal materials, researchers widely investigated pearl powder using various techniques, such as infrared (IR) spectroscopy, differential scanning calorimetry, thermal gravimetric (TG), scanning electron microscope (SEM), and X-ray diffraction (XRD) [16-25]. XRD among these techniques is a most powerful means for rapid identification on pearl powder, but it cannot detect a small amount of trace elements.
In the markets, conch powder is often faked as pearl powder on sale. Conch powder is made through fine smashing and pulverizing of clean clam shells obtained after the surface cuticles of clam shells are removed using alkali. Both pearl and conch powders are all white in color and therefore it is difficult for customers to distinguish between the two goods.

In this work, the XRD technique is used to identify the high-grade commercially available pearl layer powder and cheap street pearl powder. The ESR technique is firstly employed to monitor trace elements in pearl layer powder.

\section{EXPERIMENTAL}

The information of the samples is listed in Table 1. CAPLP is the high-grade commercially available pearl powder (80 yuan a bottle). CSPP is the cheap street pearl powder (10 yuan a bottle). Both samples were bought in a famous large mall and a small local shop, respectively. Storage: keep them under seal in two bottles.

Table 1: The information of the samples

\begin{tabular}{|ccc|}
\hline Symbol & Sample's name & place of production \\
\hline CAPLP & high-grade commercially available pearl layer powder & Zhejiang \\
CSPP & cheap street pearl powder & unknown \\
FPGP & freshwater pearl-ground powder & Jilin \\
SSGP & scallop shell ground powder & Lining \\
\hline
\end{tabular}


A freshwater pearl and scallop shells were bought in a local pearl farm and a shell farm, respectively, for comparison and identification of CAPLP and CSPP. The freshwater pearl was carefully peeled using a ceramic knife. The cuticles of scallop shells were removed using an electrical drill equipped with a round-headed grinding wheel. Then, they were pulverized and ground in agate mortar for $20 \mathrm{~min}$. The powders were screened with 100mesh screen to prepare FPGP fines, which were placed in an electronic moisture-proof cabinet for XRD or ESR measurements. The humidity in the cabinet was adjusted to $1 \%$ and the storage temperature of $18^{\circ} \mathrm{C}$.

Powder XRD measurements were performed at room temperature (RT) using a DX-2700 X-ray diffractometer (Dandong Haoyuan). All XRD data was collected between $10^{\circ} \leq 2 \theta \leq 75^{\circ}$ in steps of $0.02^{\circ}$ and the collecting time is $3 \mathrm{~s}$ per step. Each powder sample of $300 \mathrm{mg}$ was used for ESR measurements. ESR spectra were measured at RT using an A300 electronspin resonance spectrometer system (Bruker BioSpin GMBH) at an X-band frequency of $9.86 \mathrm{GHz}$. The gyromagnetic factor $(g)$ was calculated by the relationship $h v_{0}=g \beta H$, where $h$ is the Planck constant $\left(h=6.626 \times 10^{-34}\right.$ $\mathrm{J} \cdot \mathrm{s}), \nu_{0}$ is the microwave frequency, $\beta$ is the Bohr magnetron $(\beta=9.262 \times$ $\left.10^{-24} \mathrm{~J} / \mathrm{T}\right), H$ is the magnetic field strength.

\section{RESULTS AND DISCUSSION}

The powder XRD patterns of CAPLP and CSPP are shown in Figure 1. Both samples exhibited a series of diffraction peaks. Their main XRD peaks appeared at different positions $\left(2 \theta=33.22^{\circ}\right.$ and $\left.29.50^{\circ}\right)$, implying that they possessed different compositions or structures.

To identify whether CAPLP is pure pearl powder, the freshwater pearlground powder (FPGP) was prepared for comparison. The XRD patterns of CAPLP and the self-made FPGP are shown in Figure 2. Both samples had a completely same spectral structure, which provides evidence that CAPLP was really made from pulverized and ground pearls.

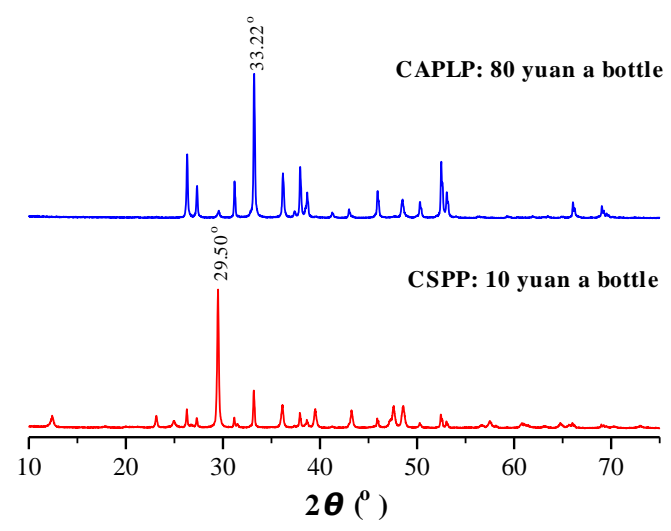

Figure 1: Powder XRD patterns of CAPLP and CSPP.

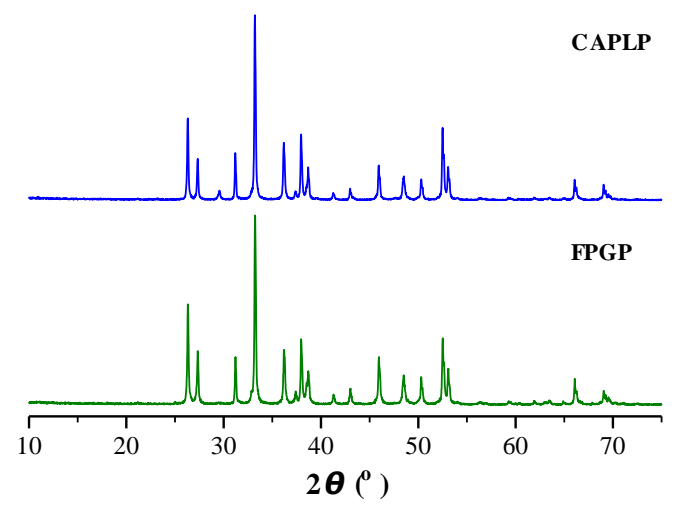

Figure 2: Comparison in XRD patterns between CAPLP and FPGP.
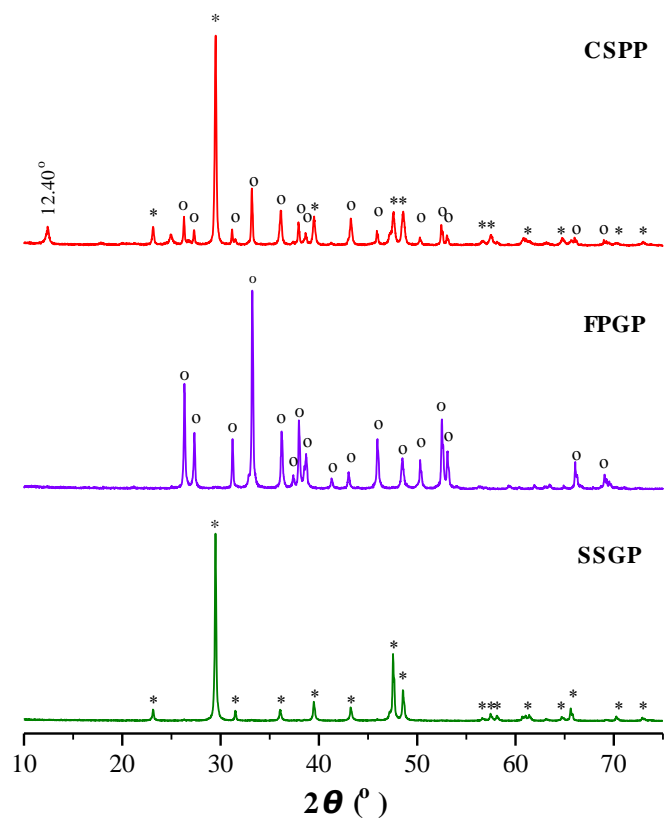

Figure 3: XRD patterns of CSPP, FPGP and scallop shell ground powder (SSGP)

It can be seen from Figure 1 that CSPP was not pure pearl powder. Considering that conch powder is often faked as pearl powder on sale, we prepared the scallop shell ground powder (SSGP) for ingredient identification of CSPP. The XRD patterns of CSPP, the self-made SSGP and FPGP are shown in Figure 3. This comparison reveals that CSPP was mainly composed of conch powder and a small amount of pearl powder, and their concentrations were $78 \%$ and $22 \%$, respectively. The appearance of an additional diffraction peak at $2 \theta=12.40^{\circ}$ suggests that other crystalline impurity existed in CSPP.

The XRD pattern of CAPLP and the simulated XRD pattern of $\mathrm{CaCO}_{3}$ (PDF: 41-1475) are shown in Figure 4, in which the miller indexes corresponding to different diffraction peaks are given. The main ingredient of pearl powder is $\mathrm{CaCO}_{3}$ [22-25]. The XRD spectrum of CAPLP is the same as that of the aragonite-type $\mathrm{CaCO}_{3}$, as shown for the simulated XRD pattern of $\mathrm{CaCO}_{3}$ (PDF: 41-1475) [24]. The main peak of CAPLP was produced by the diffraction from the (002) crystal plane, different from the simulated $\mathrm{CaCO}_{3}$ aragonite (PDF: 41-1475). This phenomenon is likely caused by the influence of amino acids and conchiolin proteins on aragonite lattice. This comparison confirms that CAPLP had an aragonite structure and existed in the form of the orthorhombic phase.

The XRD pattern of SSGP and the simulated XRD pattern of $\mathrm{CaCO}_{3}$ (PDF: 70-0095) are shown in Figure 5. This comparison confirms that our SSGP, which is different from the reported nacre powder with an aragonite structure, had a calcite structure and existed in the form of the monoclinic phase on the basis of the consistency in spectral structure of both XRD spectra [24]. 


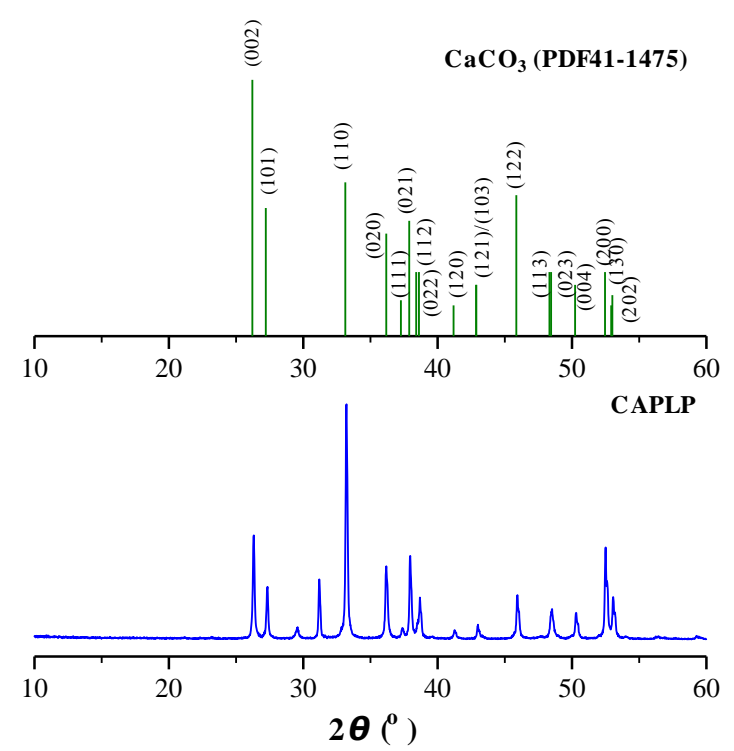

Figure 4: XRD pattern of CAPLP and the simulated XRD pattern of the orthorhombic $\mathrm{CaCO}_{3}$ (PDF: 41-1475).

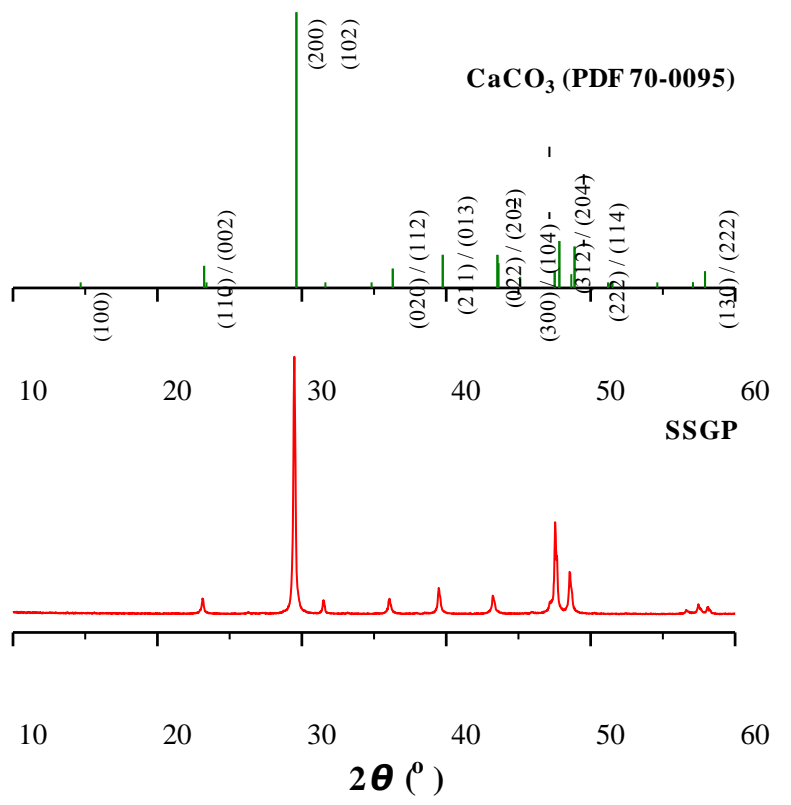

Figure 5: XRD pattern of SSGP and the simulated XRD pattern of the monoclinic $\mathrm{CaCO}_{3}$ (PDF: 70-0095).

The ESR spectra of CAPLP, CSPP, and SSGP are shown in Figure 6. A sextet signal appeared in all samples and was attributed to be $\mathrm{Mn}^{2+}$ [26]. CAPLP and SSGP exhibited the lowest and highest spectral intensities, respectively, which reveals that the concentration of $\mathrm{Mn}$ element is lowest in CAPLP and highest in SSGP. The latter is 44 times higher than the former in terms of comparison of line intensity. The high-intensity $\mathrm{Mn}^{2+}$ signal can be considered as an indication of SSGP. This comparison further confirms that the lattice of pearl layer powder contained more abundant amino acids and conchiolin proteins, which reduced the diffraction intensity.

The $\mathrm{Mn}^{2+}$ signal intensity in CSPP is 8 times higher than that in CAPLP and is between those of CAPLP and SSGP. This fact further confirms that CSPP comes from SSGP. An additional signal in CSPP appeared at $g=4.3$, which is attributed to $\mathrm{Fe}^{3+}$ impurities [27]. The strong $\mathrm{Fe}^{3+}$ signal illustrates that it is not the trace element $\mathrm{Fe}$ in CSPP, rather than $\mathrm{Fe}^{3+}$ impurities.

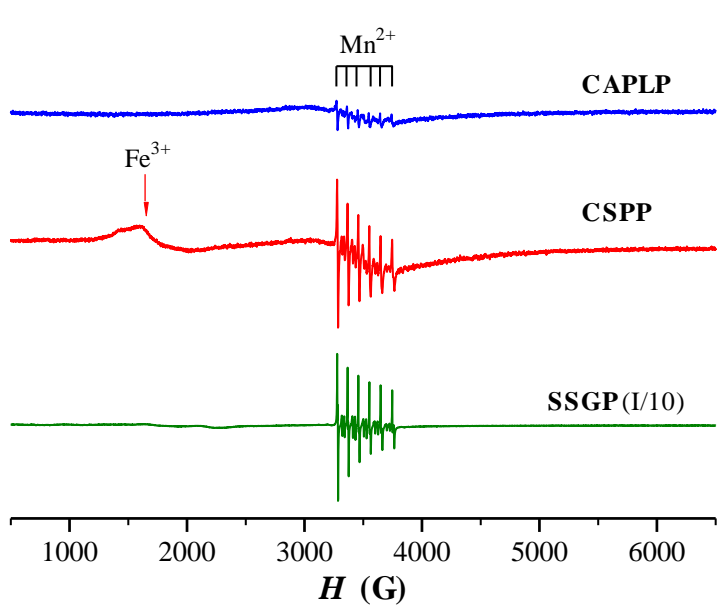

Figure 6: ESR spectea of CAPLP, CSPP and SSGP. The spectral intensity of SSGP is reduced by 10 times.

\section{CONCLUSIONS}

Both XRD and ESR techniques are combined to investigate the high-grade commercially available pearl layer powder (CAPLP) and the cheap street pearl powder (CSPP). The results indicate that CAPLP is pure pearl powder composed of calcium carbonate $\left(\mathrm{CaCO}_{3}\right)$ with an orthorhombic crystal structure, which should be fabricated by grinding freshwater pearls. CSPP is a mixture of scallop shell powder (78 \%) and pearl powder (22\%), and therefore CSPP was a fake and shoddy commodity. The major constituent of scallop shell was $\mathrm{CaCO}_{3}$ with a monoclinic crystal structure. The ESR results demonstrated that the concentration of $\mathrm{Mn}^{2+}$ in CAPLP is lowest and that is highest in scallop shell. The Fe impurities in CSPP can be also detected by ESR. The combination of XRD and ESR techniques can set up a rapid detection method for quality control of CAPLP.

\section{ACKNOWLEDGMENTS}

This work was supported by the project of Changbai Mountain Scholar Distinguished Professor (2015047).

\section{REFERENCES}

[1] National Pharmacopoeia Committee. 2015. Pharmacopoeia of People's Republic of China. Beijing: China Medical Science and Technology Press, 231-232.

[2] Bourrat, X., Francke, L., Lopez, E., Rousseau, M., Stempflé, P., Angellier, M., Albéric, P. 2007. Nacre biocrystal thermal behavior. CrystEngComm, 9 (12), 1205-1208.

[3] Yang, H.L., Korivi, M., Lin, M.K., Chang, H.C.W., Wu, C.R., Lee, M.S., Chen, W.T., Hseu, Y.C. 2017. Antihemolytic and antioxidant properties of pearl powder against 2,2'-azobis (2-amidinopropane) dihydrochloride-induced hemolysis and oxidative damage to erythrocyte membrane lipids and proteins. Journal of Food and Drug Analysis, 25 (4), 898-907.

[4] Chiu, H., Hsiao, S., Lu, Y., Han, Y., Shen, Y., Venkatakrishnan, K., Wang, C. 2018. Efficacy of protein rich pearl powder on antioxidant status in a randomized placebo-controlled trial, Journal of Food and Drug Analysis, 26 (1), 309-317.

[5] Shao, D.Z., Wang, C.K., Hwang, H.J., Hung, C.H., Chen, Y.W. 2010. Comparison of hydration, tyrosinase resistance, and antioxidant activation in three kinds of pearl powders. Journal of Cosmetic Science, 61, 133-145.

[6] Bai, J., Dai, J., Li, G. 2015. Electrospun composites of PHBV/pearl powder for bone repairing. Progress in Natural Science: Materials International, 25, 327-333.

[7] Ping, D.J., Chen, J., Xing, F.H.B., Guo, S.B. 2010. Effects of pearl powder extract and its fractions on fibroblast function relevant to wound repair. Pharmaceutical Biology, 48, 122-127. 
[8] Yang, Y.L., Chang, C.H., Huang, C.C., Liu, H.W. 2015. Anti-inflammation and anti-apoptosis effects of pearl extract gel on UVB irradiation HaCaT cells. Bio-medical materials and engineering, 26 (S1),139-145.

[9] Zhang, J.X., Li, S.R., Yao, S., Bi, Q.R., Hou, J.J., Cai, L.Y., Han, S.M., Wu, W.Y., Guo, D.A. 2016. Anticonvulsant and sedative-hypnotic activity screening of pearl and nacre (mother of pearl). Journal of Ethnopharmacology, 181, 229-235.

[10] Chen, H., Chang, J., Wu, J. 2008. Calcium bioavailability of nanonized pearl powder for adults. Journal of Food Science, 73, H246-251.

[11] Shen, Z., Kang, Y., Chen, J., Zhou, M., Lou, L., Li, G. 2010. The material set of pearl powder and triangle sail mussel shell powder classify, Metrology and Measurement, 37 (12), 69-71.

[12] Xia, J., Qian, G., Chen, L., Li, C. 2010. Analysis of chemical composition and structure characteristics of pearl and conch powders, Chemical Research and Applications, 22 (11), 1467-1471.

[13] Yan, G., Li, X., Zeng, S., Su, J., Xu, S. 2011. Fingerprints of amino acids in pearl powder by HPLC. Drugs and Clinic, 26 (6), 490-494.

[14] Pu, Y., He, J., Gao, Z., Zeng, M., Liao, B., Tong, Y. 2016. Study on the characteristics of trace elements in pearl powder and pearl layer powder, Food Research and Development, 37 (16), 125-128.

[15] Dong, N., Liang, Q., Liu, Y., Ma, K., Lv, D., Jin,, L., Hu, W. 2011. Determination of the trace element in pearl powder, Journal of Anhui Agriculture Science, 39 (1), 315-316.

[16] Xia, J., Qian, G., Chen, L., Li, C. 2010. Study on the differentiation of pearl and conch powders by FTIR. Chinese Journal of Spectroscopy Laboratory, 27 (2), 524-528.

[17] Zhang, X., Hu, C., Yan, Y., Yang, H., Li, J., Bai, H., Xi, G., Liao, J. 2014. Identification of Pearl Powder Using Microscopic Infrared Reflectance Spectroscopy. Spectroscopy and Spectral Analysis, 34 (9), 2424-2428.

[18] Zhang, X., Hu, C., Yan, Y., Yang, H., Bai,H., Xi, G., Liao, J., 2014. Qualitative identification of peal powder using near-infrared spectroscopy. Chinese
Traditional Patent Medicine, 36 (9), 1912-1915.

[19] Chen, J., li, M., Yu, K., Dong, Y., Zhang, N., Hu, X., Wei, F., Ma, S. 2015 Identication of pearl powder and conch powder from different origins by differential scanning calorimetry. Chinese Journal of Chinese Materia Medica, 40 (8),1459-1462.

[20] Yan, J., Fang, B., Wang, X., Zhang, X., Yu, D., Hu, X., 2015. Microstructure and spectroscopic characteristics of shell and pearl powder from Hyriopsis Cumingii. PTCA (PART: Chemistry Analysis), 51 (2), 137-141.

[21] Shen, Z., Kang, Y., Chen, J., Zhou, M., Lou, L., Li, G. 2010. The material set of pearl powder and triangle sail mussel shell powder classify. Metrology and Measurement, 37 (12), 69-71.

[22] Li, H., Han, M., Zhu, F., Song, J., Zhang, C. 2013. Identification of pearl powder from Zhejiang by scanning electron microscope and X-ray diffraction analysis. Chinese Journal of New Drugs, 22 (23), 2817-2821.

[23] Wang, Y., Han, M., Ge, E., Ma, Q., Zhou, D. 2011. Identification of Fourier finger pattern on pearl powder by XRD. Chinese Journal of Experimental Traditional Medical Formulae, 17 (20), 105-108.

[24] Fang, P., Jin, X., Wang, L. 2017. On identification of freshwater pearl and nacre powder based on XRD. Journal of Shao Xing University, 37 (7), 74-78.

[25] Qiu, Y., Liao, J. 2014. Discrimination of pearl powder and conch powder by high-temperature XRD. PTCA (Part B: Chemical Analyses), 50 (3), 294-297.

[26] Lu, D., Guan, D., Li, H. 2018. Multiplicity of photoluminescence in Raman spectroscopy and defect chemistry of $\left(\mathrm{Ba}_{1-x} R_{x}\right)\left(\mathrm{Ti}_{1-x} \mathrm{Ho}_{x}\right) \mathrm{O}_{3}(R=$ $\mathrm{La}, \mathrm{Pr}, \mathrm{Nd}, \mathrm{Sm}$ ) dielectric ceramics. Ceramics International, 44 (2), 14831492.

[27] Kutty, T.R.N., Murugaraj, P., Gakbhiye, N.S. 1985. EPR evidence for activation of trap centers in PTCR $\mathrm{BaTiO}_{3}$ ceramics. Materials Research Bulletin, 20, 565-574.

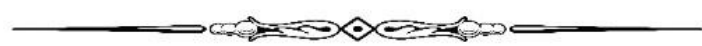

